\title{
Converting Faculty Performance Evaluations Into Merit Raises: A Spreadsheet Model
}

Elizabeth B. Davis (E-mail: Elizabeth_davis@baylor.edu), Baylor University John T. Rose (E-mail: jt_rose@baylor.edu), Baylor University

\begin{abstract}
One of the most important, yet difficult tasks of any academic department chairperson is to evaluate the annual performance of individual faculty members and then to convert the array of performance evaluations into a structure of merit raises. Building on previous literature, this paper presents a spreadsheet model to convert qualitative performance evaluations into merit raises subject to 1) a limited pool of funds for salary adjustments and 2) a requirement that the relative structure of percentage raises match the relative structure of performance evaluations as defined by a linear evaluation scale. The contribution of the paper is its practical nature in that the proposed spreadsheet can immediately be put to use by academic chairpersons, is readily understandable by the faculty, and is useful for all institutions with various combinations of teaching, research, and service expectations for the faculty.

To match the structure of raises with that of performance evaluations, qualitative evaluations in each of the three areas of faculty performance-teaching, research, and service-are first converted into numeric equivalents based on a linear evaluation key. Next, the numeric equivalents are weighted according to a weighting scheme dependent on the amount of release time provided to the faculty member for research and/or service, in order to generate an overall numeric evaluation for each faculty member. Finally, the weighted numeric evaluations are converted into percentage merit raises subject to a finite salary adjustment pool using the Goal Seek function in Microsoft Excel. The model is illustrated using a hypothetical department of ten faculty members with varying teaching loads and thus different amounts of release time for research and/or service.
\end{abstract}

\section{Introduction}

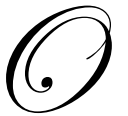

ne of the most important, yet difficult tasks of any academic department chairperson is to assign a structure of merit raises to the department faculty based on performance evaluations of individual faculty members. Essentially, this task involves three steps: 1) defining and collecting relevant performance data on each faculty member, 2) evaluating faculty members based on the data collected, and 3) converting qualitative performance evaluations into merit pay increases (Koehler 1986). Determining the relevant performance data depends importantly on what is expected of the faculty, which in turn depends on an institution's mission. Certainly, faculty expectations and the associated performance data will differ sharply between a small college with a predominantly teaching mission and a large university with a heavy emphasis on research. Likewise, performance evaluations of faculty members may vary across institutions, and even across departments within the same institution, depending on the institution's standards for high, medium, and low performance and the ability of department chairs to apply those standards in assessing individual performance. Finally, converting performance evaluations into merit pay increases introduces questions about how to treat existing salary levels, but otherwise performance-based raises can be determined objectively, and several models have been suggested to provide guidance in this effort. 
This paper presents a Microsoft Excel spreadsheet model to convert qualitative performance evaluations into merit raises. ${ }^{1}$ As such, it satisfies the objectives of most previous salary adjustment models, but with minimal algebraic calculations. The contribution of the paper is its practical nature in that the proposed spreadsheet can immediately be put to use by academic administrators and is readily understandable by the faculty. The spreadsheet is useful for institutions of all Carnegie classifications, accommodating schools with tenured/tenure-track faculty as well as non-tenured/tenure-track faculty and with various combinations of teaching, research, and service expectations for the faculty.

The next section reviews the literature relating to the issue of linking qualitative performance evaluations to salary adjustments. The third section then presents a spreadsheet model for converting performance evaluations into percentage raises subject to a finite salary adjustment pool. Several extensions of the model are presented in the fourth section, followed by a summary and conclusion.

\section{Literature Review}

Existing models that link performance evaluations to salary adjustments typically assume a limited pool of funds for merit raises and then focus on how that pool should be allocated (Hansen 1988). ${ }^{2}$ The result is a pay increase for each faculty member calculated as either a dollar increment or a percentage increment. To illustrate, consider a department of two faculty members, A and B. Faculty member A earns a relatively high salary $(\$ 60,000$ per year) and demonstrates satisfactory performance while faculty member B earns a relatively low salary $(\$ 44,000$ per year) but demonstrates outstanding performance. Assume further that B's performance evaluation is twice as good as A's, as measured by some linear evaluation scale, so B should receive twice the salary increment of A. If the pool for merit raises is $8 \%$ of the total department base salary $(\$ 104,000)$, or $\$ 8,320$, and raises are awarded as dollar increments, then B should receive two-thirds of the merit pool or $\$ 5,547$ (a $12.6 \%$ raise) and A should receive one-third of the pool or $\$ 2,773$ (a $4.62 \%$ raise). On the other hand, if raises are awarded as percentage increments, then $\mathrm{B}$ should receive a raise of $11.24 \%(\$ 4,947)$ and A should receive a raise of $5.62 \%$ raise $(\$ 3,373) .{ }^{3}$ Under either arrangement, faculty member B would receive "twice" the raise of A-twice the dollar raise in the first case and twice the percentage raise in the second case. This example illustrates the observation by McIntosh and Van Koevering (1986) that a dollar increment merit pay system favors faculty in the lower ranks (or at least at the lower end of the salary range) who outperform faculty in the higher ranks (or the higher end of the salary range) because the higher dollar award from such a salary adjustment system generates a faster salary growth rate for highperformance, lower-paid faculty than a percentage increment merit pay system.

So which type of merit raise system is better? Virtually all salary adjustment models focus on merit increments as a percentage of one's base salary. The justification for a percentage increment merit pay system is perhaps best articulated by Camp, Gibbs, and Masters (1988), who argue that awarding raises as fixed dollar increments is fundamentally flawed because the raises generated under such a system ignore an individual's existing, or base, salary. The authors support their position on the theory that a faculty member's salary provides a return on his investment in human capital, where such investment is based on professional experience, among other things. Therefore, another year of experience adds to one's human capital investment, requiring a percentage increment raise equal to the percentage increase in human capital in order to maintain the expected return on the faculty member's total human capital investment. To illustrate, suppose a faculty member has a total human capital investment of $\$ 700,000$ and earns an annual salary of $\$ 70,000$ for a 10 percent annual return. Assume further that another year of experience adds five percent, or $\$ 35,000$, of additional human capital. To maintain a constant annual return on the faculty member's total human capital, he should therefore receive a salary increase of five percent of $\$ 70,000$ or $\$ 3,500$, giving him a total annual salary of $\$ 73,500$ for a 10 percent return on his total human capital investment of $\$ 735,000$. Based on this theoretical underpinning, Camp, Gibbs, and Masters propose a merit raise system using an algebraic model designed to assign a structure of percentage raises to multiple faculty members with various base salary levels and different performance evaluations subject to 1) a limited pool of funds for salary adjustments and 2) a requirement that the relative structure of percentage raises match the relative structure of performance evaluations as defined by a linear evaluation scale. 
Weistroffer, Spinelli, Canavos, and Fuhs (2001) extend the Camp-Gibbs-Masters analysis with a more elaborate performance evaluation system that includes eight teaching criteria and weights, four research criteria and weights, and three service criteria and weights. The weighted criteria are converted into an evaluation score for each area of performance, from which a composite score is derived. This composite score, in turn, is used to determine one's percentage increment raise in a manner similar to Camp-Gibbs-Masters. The authors note that this model is flexible enough to allow faculty members to focus on their relative strengths consistent with the objectives of the department and the university. However, they also point out that the model is designed for a faculty workload incorporating all three areas of traditional faculty activity and would not work well for a workload focused on teaching and/or service, thereby precluding the usefulness of the model for many institutions.

In another extension of Camp-Gibbs-Masters, Wenger and Girard (2000) recognize that a department chair may desire to constrain the salary increase of a faculty member at the lower or upper end of the percentage raise spectrum. For example, suppose the Camp-Gibbs-Masters model would award a raise of, say, three percent to the faculty member receiving the lowest performance evaluation, but the department chair desires to give no more than a one percent raise to that faculty member. Wenger and Girard attempt to impose such a constraint by modifying the algebra of the Camp-Gibbs-Masters model, in effect reallocating the remaining salary adjustment pool after assigning a one percent pay increase to the target faculty member. The result is to create a wider spread of percentage raises across the department faculty than would otherwise be awarded by Camp-Gibbs-Masters. Alternatively, a chairperson could decide that a faculty member's calculated raise is too low, in which case the chair might set a higher raise for that faculty member, resulting in a narrower spread of percentage raises across the faculty. In both instances, however, the resultant relative structure of percentage raises would no longer match the relative structure of performance evaluations.

Although the Wenger-Girard model results in an adjusted percentage raise for the targeted faculty member, as well as for all other faculty members in the department, what the model really adjusts is the array of evaluation scores. Not only does the model lower the merit percentage raise awarded to the weakest faculty member, but it also adjusts downward any faculty member's raise with an evaluation score below the mean and adjusts upward any faculty member's raise with an evaluation score above the mean. The implication is that the evaluation scores no longer accurately reflect the relative performance evaluations of the faculty members in the department. In situations such as these, it may be more appropriate for the department chair to re-collect and/or re-analyze the performance data on individual faculty members in order to adjust the array of performance evaluations directly rather than indirectly through adjusted merit raises.

Still another approach to setting merit raises is suggested by Becker (1999), who argues that sometimes it is appropriate to utilize a dollar increment merit pay system. He reasons that the difference between percentage increment raises and dollar increment raises is non-trivial to some faculty and thus may be de-motivating. Specifically, he suggests that a faculty member at the lower end of the salary range may conclude that no matter how productive he is, he can never catch up to the higher-salaried faculty when raises are calculated as a percentage of

base salary. ${ }^{4}$ Conversely, dollar increment merit pay models result in salary compression that may be de-motivating to higher-salaried faculty. As a result, higher-paid (and often higher ranking) faculty may allow their productivity to wane if they do not believe they are being rewarded appropriately.

In recognition of these competing objectives, Becker proposes a model that splits a salary adjustment pool into a portion to be allocated by percentage increments and another portion to be allocated by dollar increments. The relative amounts of the pool for percentage increments and dollar increments is left to the discretion of the department chair. However, it is easy to generate alternative scenarios ranging from $100 \%$ dollar increment and no percentage increment to $100 \%$ percentage increment and no dollar increment in order to identify the effects of different scenarios on the various faculty members.

\section{A Spreadsheet Model}

The proposed spreadsheet model for converting faculty performance evaluations into merit raises incorporates the same linear matching requirement as Camp-Gibbs-Masters, namely, that the relative structure of 
percentage raises should match the relative structure of performance evaluations across the faculty. To accomplish this matching, qualitative evaluations in each of the three areas of faculty performance - teaching, research, and service - are first converted into numeric equivalents based on a linear evaluation key. Next, the numeric equivalents are weighted according to a scheme dependent on the amount of release time provided to the faculty member for research and/or service, in order to generate an overall numeric evaluation for each faculty member. Finally, the weighted numeric evaluations are converted into percentage merit raises subject to a finite salary adjustment pool using the Goal Seek function in Microsoft Excel.

To illustrate, consider a hypothetical academic department with ten faculty members with varying teaching loads and thus different amounts of release time for research and/or service. Assume further that the department has a total salary budget for academic year 2002-03 of $\$ 800,000$, and the University Administration has budgeted a merit raise pool for 2003-04 of 7 percent of the department's total 2002-03 salary, or $\$ 56,000$. Calculations of the merit raises for the department faculty are presented in the spreadsheet shown in Figures 1 and 1A. Figure 1 shows the calculated numbers; Figure 1A shows the formulas underlying the calculated numbers.

The first section of the spreadsheet (column A) lists the ten faculty members and their annual teaching loads expressed in terms of the number of course sections taught in the fall, spring and summer sessions. Thus, a teaching load of 2-2-0 is two course sections in the fall, two in the spring, and none in the summer. The second section (columns B - D) gives the qualitative evaluation, ranging from Unsatisfactory to Outstanding, of each faculty member's performance in each of the three areas of performance-teaching, research, and service-for calendar year 2002. The third section (columns E-G) converts the qualitative evaluations into numeric evaluations based on the evaluation key presented in the lower left-hand corner of the spreadsheet. Any linear range of numeric scores could be used to define the evaluation key. For simplicity, we chose a range of satisfactory scores from zero to four, that is, Fair $=0$, Good $=1$, Very Good $=2$, Excellent $=3$, and Outstanding $=4$. Unsatisfactory is then given a score of -1 . As will be seen later, the effect of this range of scores is to assign a positive merit raise to anyone receiving an overall evaluation above Fair, a zero raise to anyone receiving an overall evaluation of Fair, and a negative raise (essentially, a reduction in the faculty member's base salary) to anyone receiving an overall evaluation below Fair.

The fourth section of the spreadsheet (columns $\mathrm{H}-\mathrm{K}$ ) provides a weighting scheme for the three areas of faculty evaluation according to the amount of release time provided to a faculty member for research and/or service. ${ }^{5}$ Assuming a full teaching load consistent with the academic tradition of 10 course sections per year -4 sections in the fall, 4 in the spring, and 2 in the summer-and a 10 percent weighting for service for all faculty members (unless someone has additional time assigned specifically for service), that leaves a 90 percent weighting to be allocated between teaching and research in units of 9 percent for each section taught or released for research. Thus, in the case of Jones (row 7) with a full teaching load of 4-4-2, his evaluation for teaching would be weighted as $10 \times 9 \%=90 \%$ while his evaluation for research would be weighted as zero since he receives no time for research. By contrast, in the case of Bleecher (row 13) with a 2-2-0 teaching load, her evaluation for teaching would be weighted as $4 \times 9 \%=36 \%$ and her evaluation for research would be weighted as $90 \%-36 \%=54 \%$ since she receives six course sections of time for research $(6 \times 9 \%=54 \%)$. And finally, in the case of Pittman (row 16) with a 2-2-0 teaching load, two course sections of time for research, and four course sections of time for service (perhaps as department chair), his evaluation for teaching would be weighted as $4 \times 9 \%=36 \%$ while his evaluation for research would be weighted as $2 \times 9 \%=18 \%$ and his evaluation for service would be weighted as $4 \times 9 \%=36 \%$ plus the $10 \%$ for service required of everyone for a total service weighting of $46 \%$. The implication of this weighting scheme is that every faculty member is evaluated on both teaching and service, and faculty members with time for research or additional service are also evaluated on their research or added service output, recognizing the amount of time they have been provided for such research or additional service. ${ }^{6}$

Weighting the numeric evaluations (columns E - G) by the appropriate weights, as determined by the time given for research and/or additional service (columns $\mathrm{H}$ - J), gives 1) a weighted numeric evaluation (column L) and 2) the weighted numeric evaluation as a percent of the maximum possible numeric evaluation of 4.0 (column $\mathrm{M}$ ). Thus, for example, Smith's evaluations (row 8) for teaching $(\mathrm{G} / \mathrm{VG})$, research $(\mathrm{O})$, and service $(\mathrm{E})$ translate into a weighted numeric evaluation of 3.0 , representing $75 \%$ of the maximum possible numeric evaluation of 4.0 . 
The next section of the spreadsheet converts the weighted numeric evaluations (column M) into 2003-04 dollar merit increases (column $\mathrm{N}$ ) such that the percentage increment raises (column $\mathrm{O}$ ) maintain the same relative relationship to one another as the weighted numeric evaluations. Thus, faculty members receiving the same weighted numeric evaluation, such as Smith and Pittman, each of whom received a weighted numeric evaluation of 3.0, should receive the same percentage merit raise. Likewise, Bleecher, who received a weighted numeric evaluation of 3.9, should receive a percentage merit raise six times that of Oden, who received a weighted numeric evaluation of only 0.65 . This can be accomplished with three simultaneous calculations. First, for each faculty member his/her 2003-04 dollar merit increase (column N) is defined as equal to the product of 1) his/her weighted numeric evaluation as a percent of the maximum possible evaluation of 4.0 (column $\mathrm{M}$ ) times 2) the maximum possible percentage merit increase for an overall evaluation of Outstanding times 3 ) the faculty member's 2002-03 salary (column P). Second, the total dollar amount available for merit increases (cell N17) is defined as the sum of the merit increases of all the faculty members (cells N7 through N16). And third, using the Goal Seek function in Excel, the total dollar amount available for merit increases (cell N17) is set equal to $\$ 56,000$ by changing the maximum possible percentage merit increase for an overall evaluation of Outstanding. ${ }^{7}$ (This set of simultaneous calculations is summarized in the lower right-hand corner of Figure 1 with cell P24 designated as the maximum possible percentage merit increase for an overall evaluation of Outstanding. ${ }^{8}$ ) In the present example the maximum possible percentage merit increase for an overall evaluation of Outstanding turned out to be $12.00 \%$, giving Smith (row 8) a percentage raise of $9.00 \%$ (cell O8), the same percentage raise as Pittman (cell O16), who had the same weighted numeric evaluation, as noted earlier. Similarly, Bleecher (row 13) would receive a percentage merit increase of $11.70 \%$ (cell O13), six times that of Oden's percentage raise of 1.95\% (cell O12), which is consistent with the relative difference in their weighted numeric evaluations.

Two final points should be made about the percentage raises shown in column O. First, the array of calculated raises is identical to that which would be generated by the algebraic model proposed by Camp, Gibbs, and Masters. ${ }^{9}$ Second, the variance in percentage raises depends ultimately on the variance in qualitative evaluations, as converted into weighted numeric evaluations. Thus, if there were no variance in the qualitative evaluations, then all faculty members would receive the same percentage raise regardless of whether they all received an overall evaluation of Fair or Outstanding. While this is a potential weakness of the model, in practice it should not pose a problem if department chairs make appropriate distinctions in the performance assessments of the faculty in their departments.

The remaining columns in the spreadsheet complete the calculations. Adding the dollar merit increase of each faculty member (column N) to his/her 2002-03 salary (column P) gives the total recommended 2003-04 salary for the faculty member (column Q).

\section{Extensions Of The Model}

In this section we extend the spreadsheet model presented above to demonstrate how it might be adapted to address various issues faced by a department chair. For example, notice in Figure 1 that Wilson (row 9) has a numeric evaluation of zero (cell L9), reflecting an overall evaluation of Fair, which would result in a zero raise (cells N9 and O9). Suppose, however, that the department chair wishes to set a minimum non-zero raise, say, one percent, for any faculty member performing satisfactorily, i.e., receiving an overall evaluation of Fair. To impose this constraint, we amended the equation in cell N9 to force Wilson's merit increase to one percent and then used Goal Seek to re-solve for the appropriate merit increases for all of the other faculty members; see Figure 2. Notice that the total salary adjustment pool is still $\$ 56,000$, but all the other faculty members' merit increases are reduced due to the reallocation of $\$ 1,000$ from their collective raises (as calculated in Figure 1) to provide a one percent raise for Wilson. In other words, the pool of funds available to the other nine faculty members is now $\$ 55,000$. It should be emphasized that this adjustment is not the same as that proposed by Wenger and Girard (2001) because the weighted numeric evaluations of the other faculty members have not changed, implying that they were determined correctly in the first place. As a result, the relative structure of percentage raises among all the faculty members except Wilson continues to match the relative structure of performance evaluations of these faculty, just as it did for all the faculty in Figure 1. 
Another extension of the basic spreadsheet model captures Becker's (1999) suggestion that the salary adjustment pool should be split into a portion to be allocated by percentage increments and another portion to be allocated by dollar increments. Figure 3 thus illustrates the scenario in which the total merit pool of $\$ 56,000$ is divided such that 60 percent $(\$ 33,600)$ is reserved for percentage increment raises and 40 percent $(\$ 22,400)$ is set aside for dollar increment raises. Figure 3 is identical to Figure 1 through column $\mathrm{O}$ except that the total amount of percentage increment raises (cell N17) is reduced to $\$ 33,600$ with proportionate reductions in the percentage increment increases of each faculty member. Thus, for example, the percentage increment merit raise of Jones is now 5.58\% (cell O7), exactly 60 percent of the $9.30 \%$ percent raise calculated for Jones in Figure 1. Column P is then used to calculate a dollar increment merit raise for each faculty member, computed as the product of 1) the weighted numeric evaluation (column L) as a percent of the sum of the weighted numeric evaluations of all the faculty (L7 through L16) times 2) the \$22,400 reserved for dollar increment merit increases. Finally, as in Figure 1, the remaining columns complete the calculations. Adding the two dollar merit increases of each faculty member (columns $\mathrm{N}$ and $\mathrm{P}$ ) give the total dollar and percentage merit increases (columns $\mathrm{Q}$ and R, respectively), which when added to his/her 2002-03 salary (column S) gives the total recommended 2003-04 salary for the faculty member (column T).

Once again, the total salary adjustment pool of $\$ 56,000$ was fully distributed to the faculty, but the final structure of raises differs from that calculated in Figure 1. For example, notice in Figure 3 that Smith (row 8) and Pittman (row 16) again received the same percentage increment merit raise (in this case, 5.4\%), which is consistent with their identical weighted numeric evaluations. However, since Smith has a higher base salary than Pittman, $5.40 \%$ translates into more dollars for Smith $(\$ 3,780$ versus $\$ 3,240$ for Pittman). By contrast, the dollar increment merit raise calculated in column $\mathrm{P}$ is $\$ 2,808$ for both Smith and Pittman, representing equal dollars for equal performance. Although Smith still receives a higher total dollar raise than Pittman, the difference in dollar raises is narrower than that calculated in Figure 1, and Smith now receives a lower total percentage raise than Pittman. Whether this approach represents an appropriate means for allocating a pool of salary adjustment funds, of course, depends ultimately on the department's and/or the university's goals for faculty compensation.

Still another extension of the basic spreadsheet model demonstrates how to allocate a salary adjustment pool when a portion of the pool is to be given as an across-the-board cost of living (COLA) increase and the remainder is to be awarded as percentage increment merit raises. Assume from the original example that the University Administration intends to divide the $\$ 56,000$ salary adjustment pool into a 3 percent COLA increase $(\$ 24,000)$ and a 4 percent merit pool $(\$ 32,000)$. Calculations of the salary increases for each of the faculty members in the department are presented in the spreadsheet shown in Figure 4. Again, Figure 4 is identical to Figure 1 through column $\mathrm{O}$ except that the total amount of percentage increment raises (cell N17) is reduced to $\$ 32,000$ with proportionate reductions in the percentage increment increases of each faculty member. For example, Smith and Pittman now receive merit raises of only 5.14\% compared to $9.00 \%$ when the entire salary adjustment pool was distributed as merit raises (Figure 1). Column P provides the simple computation of 3\% of each faculty member's base salary, exhausting the COLA pool of $\$ 24,000$. Finally, as in Figure 3, the remaining columns complete the calculations. Adding the dollar merit increase (column N) and the COLA increase (column P) of each faculty member gives the total dollar and percentage merit increases (columns Q and R, respectively), which when added to his/her 2002-03 salary (column S) gives the total recommended 2003-04 salary for the faculty member (column T).

\section{Summary And Conclusion}

One of the most important, yet difficult tasks of any academic department chairperson is to evaluate the annual performance of individual faculty members and then to convert the array of performance evaluations into a structure of merit raises. This paper presents a Microsoft Excel spreadsheet model to convert qualitative performance evaluations into merit raises. As such, it satisfies the objectives of most previous salary adjustment models, but with minimal algebraic calculations.

Previous merit raise models have generally focused on pay increases as a percentage of one's base salary. The proposed spreadsheet model also focuses on percentage increment raises and incorporates a traditional linear matching requirement, namely, that the relative structure of percentage raises should match the relative structure of 
performance evaluations across the faculty. To accomplish this matching, qualitative evaluations in each of the three areas of faculty performance - teaching, research, and service - are first converted into numeric equivalents based on a linear evaluation key. Next, the numeric equivalents are weighted according to a scheme dependent on the amount of time provided to the faculty member for research and/or service, in order to generate an overall numeric evaluation for each faculty member. Finally, the weighted numeric evaluations are converted into percentage raises subject to a finite salary adjustment pool using the Goal Seek function in Microsoft Excel.

The model is illustrated using a hypothetical academic department with ten faculty members with varying teaching loads and thus different amounts of time for research and/or service. Additionally, the model is extended to demonstrate how it might be adapted to address various issues faced by a department chair.

In conclusion, the real contribution of this paper is its practical nature in that the proposed spreadsheet can immediately be put to use by academic administrators and is readily understandable by the faculty. Furthermore, the spreadsheet is useful for institutions of all Carnegie classifications, accommodating schools with tenured/tenuretrack faculty as well as non-tenured/tenure-track faculty and with various combinations of teaching, research, and service expectations for the faculty.

\section{Endnotes}

1. Numerous previous studies have looked at the issue of how to evaluate faculty performance; see, for example, Brown (1984) and Hecht, Higgerson, Gmelch, and Tucker (1999). For purposes of this study we assume the department chair has already completed qualitative performance evaluations of the faculty and seeks to convert those evaluations into merit raises.

2. In a very different approach from the studies discussed here, Koehler (1986) developed a logistic-type salary growth model based on four criteria-level of education and/or training, years of pertinent experience, level of performance and/or potential, and marketability of discipline and/or specialty. Although his model can be used to objectively determine salaries, it is quite complex and requires significant data collection. Similarly, Mesak and Jauch (1991) developed a multi-criteria evaluation model to map measures of research, teaching, and service into a performance measure for each faculty member. This performance measure is combined with a relative market value of the faculty member, and through an iterative process an appropriate ranking of faculty can be determined which ultimately results in the allocation of a pool of merit funds. The procedure is complex and may be difficult to put in practice by administrators other than those trained in the decision sciences.

3. These percentages were determined by solving the following equation for $\mathrm{X}$, where $\mathrm{X}$ is the percentage raise to be received by faculty member $A$ : $\$ 60,000(X)+\$ 44,000(2 X)=\$ 8,320$. Solving the equation gives $X=$ $5.62 \%$ (the percentage raise for $\mathrm{A}$ ) and $2 \mathrm{X}=11.24 \%$ (the percentage raise for $\mathrm{B}$ ).

4. Another argument against percentage increment pay increases is presented by McIntosh and Van Koevering (1986), who conclude that when merit raises are so low that percentage increments will have virtually no effect on the salary of any faculty member, then dollar increment raises are a more appropriate means of reward.

5. For a recent listing of the teaching-research-service weighting schemes used in awarding tenure by the economics departments in a sample of 15 private universities, see Dearden, Taylor, and Thornton (2001). None of the surveyed departments appears to use a weighting scheme specifically linked to the amount of time provided for research.

6. This is not to suggest that there should be no expectation of any research output from a faculty member with a full (4-4-2) teaching load. Some minimal amount of research activity is still important for faculty development to maintain one's expertise in his/her teaching area. There remains, however, the issue of how to reward appropriately a faculty member with a full teaching load who generates more than the minimal amount of expected research but whose evaluation score provides no weight for research productivity. In such cases, the department chair could recommend a supplemental salary increase - in addition to any merit raise for teaching - to be paid by the dean or provost.

7. The Goal Seek function may be accessed by clicking on Tools at the top of the Excel screen and then scrolling down to Goal Seek. 
8. Any empty cell could have been selected to fulfill the purpose of cell P24, which is to hold the maximum possible percentage merit increase for an overall evaluation of Outstanding in the Merit Increase formulas in column $\mathrm{N}$.

9. To illustrate, let us calculate the percentage merit raises for Oden and Bleecher (from Figure 1) using the CampGibbs-Masters model. The Camp-Gibbs-Masters model defines M, the dollar merit increase, as the product of $\rho^{*} \mathrm{~F}$, where $\rho$ is the product of three variables, $\mathrm{B}^{*} \mathrm{P}^{*} \mathrm{~K}$, and $\mathrm{F}$ is the total dollar pool available for merit raises, in this case $\$ 56,000$. B is an individual professor's salary as a percent of the total current department salary budget, in this case $\$ 800,000$. $\mathrm{P}$ is an individual professor's performance rating as a percentage of the total (summed) performance ratings of the department faculty, in this case the sum of the weighted numeric evaluations in column L of Figure 1. Finally, $\mathrm{K}$ is the inverse of $\Sigma\left(\mathrm{B}^{*} \mathrm{P}\right)$ across the department faculty. Presented below are the several variables for Oden and Bleecher, along with the calculated dollar and percentage merit increases which are identical to those presented for these faculty members in Figure 1.

$\begin{array}{llll}\frac{\text { Oden }}{\mathrm{B}} & =(90,000 / 800,000)=.1125 & \frac{\text { Bleecher }}{} & \\ \mathrm{P} & =(0.65 / 23.93)=.0272 & \mathrm{~B} & =(110,000 / 800,000)=.1375 \\ \mathrm{~K} & =10.25663 & \mathrm{P} & =(3.90 / 23.93)=.1630 \\ \mathrm{P}=\mathrm{B} * \mathrm{P} * \mathrm{~K} & =.1125 * .0272 * 10.25663=.0313 & \mathrm{~K} & =10.25663 \\ \mathrm{M}=\rho^{*} \mathrm{~F} & =.0313 * 56,000=\$ 1,755 & \mathrm{P}=\mathrm{B} * \mathrm{P} * \mathrm{~K} & =.1375 * .1630 * 10.25663=.2298 \\ \text { Merit } \% & =(1,755 / 90,000)=1.95 \% & \mathrm{M}=\rho^{*} \mathrm{~F} & =.2298 * 56,000=\$ 12,871 \\ & & \text { Merit } \% & =(12,871 / 110,000)=11.70 \%\end{array}$

\section{Please contact authors to view figures.}

\section{References}

1. Becker, William E. (1999). “Turning merit scores into salaries”, Journal of Economic Education, vol. 30, no. 4 (Fall), pp. 420-426.

2. Brown, William S. (1984). "Performance review instruments and merit pay programs in an academic environment", The Journal of the College and University Personnel Association, vol. 35 (Spring), pp. $7-13$.

3. Camp, Robert C., Manton C. Gibbs, Jr., and Robert J. Masters II. (1988). "The finite increment faculty merit pay allocation model", Journal of Higher Education, vol. 59, no. 6 (November/December), pp. 652-667.

4. Dearden, James, Larry Taylor, and Robert Thornton (2001). "A benchmark profile of economics departments in 15 private universities", Journal of Economic Education, vol. 32, no. 4 (Fall), pp. 387-396.

5. Hansen, W. Lee (1988). "Merit pay in higher education", in D.W. Breneman and T.I.K. Youn (eds.), Academic Labor Markets and Careers. Philadelphia: The Falmer Press, pp. 114-137.

6. Hecht, Irene W. D., Mary Lou Higgerson, Walter H. Gmelch, and Allan Tucker (1999). The Department Chair As Academic Leader. Phoenix, AZ: American Council on Education and Oryx Press.

7. Koehler, W. F. (1986). "From evaluations to an equitable selection of merit-pay recipients and increments", Research in Higher Education, vol. 25, no. 3, pp. 253-263.

8. McIntosh, Thomas H. and Thomas E. Van Koevering (1986). "Six-year case study of faculty peer reviews, merit raises, and pay awards in a multi-disciplinary department", Journal of the College and University Personnel Association, vol. 37 (Spring), pp. 5-14.

9. Mesak, Hani I. and Lawrence R. Jauch (1991). "Faculty performance evaluation: Modeling to improve personnel decisions", Decision Sciences, vol. 22, no. 5 (November/December), pp. 1142-1157.

10. Weistroffer, H. Roland, Michael A. Spinelli, George C. Canavos, and F. Paul Fuhs (2001). "A merit pay allocation model for college faculty based on performance quality and quantity", Economics of Education Review, vol. 20, no.1 (February), pp. 41-49.

11. Wenger, Robert B. and Dennis M. Girard (2000). "A faculty merit pay allocation model", Research in Higher Education, vol. 41, no. 2 (April), pp. 195-207. 